\title{
Robust Control of Doubly Fed Induction Generator Using Fractional Order Control
}

\author{
Abdelaziz Azza ${ }^{1}$, Hamid Kherfane ${ }^{2}$ \\ ${ }^{1}$ LASA Laboratory, Department of Electronics, Badji Mokhtar-Annaba University, Annaba, Algeria \\ ${ }^{2}$ L2RCS Laboratory, Department of Electronics, Badji Mokhtar-Annaba University, Annaba, Algeria
}

\begin{abstract}
Article Info
Article history:

Received Feb 27, 2018

Revised May 2, 2018

Accepted Jul 1, 2018

\section{Keyword:}

DFIG

FOPI

Fractional order control

ABSTRACT

In this paper, we present a robust control of a variable speed Doubly Fed Induction Generator (DFIG)-based Wind Energy Conversion System (WECS), using Fractional Order Control (FOC) to prevent system deterioration under different critical conditions (external disturbance, measurement noise and DFIG parameters variation). In order to extract the maximum power from the wind, a Maximum Power Point Tracking (MPPT) strategy based on rotor speed control is proposed. Furthermore, a vector control strategy is used for controlling active and reactive powers of DFIG. Additionally, a simple design method of Fractional Order Proportional Integral (FOPI) controller is proposed. Finally, the system's performance is tested and compared according to reference tracking, robustness, disturbance rejection and noise minimization.
\end{abstract}

MPPT

Vector control strategy
Copyright $(0) 2018$ Institute of Advanced Engineering and Science. All rights reserved.

\section{Corresponding Author:}

Abdelaziz Azza,

LASA Laboratory,

Department of Electronics,

Badji Mokhtar-Annaba University,

P.O. Box 12, 23000 Annaba, Algeria

Email: mamaabdelaziz@yahoo.fr

\section{INTRODUCTION}

Nowadays, a majority of the wind energy conversion systems utilize doubly fed induction generator because of its high efficiency and low cost owing to its configuration [1], [2]. DFIG have windings on both stator and rotator parts, where both of them transfer considerable power between generator and grid. In DFIG, the converters process only about $20-30 \%$ of total generated power, and the rest is fed to the grid directly from the stator [3]-[5].

Usually, DFIG is controlled using vector control strategy, which is either stator voltage oriented, or stator flux oriented. This scheme decouples nonlinear Multiple Input Multiple Output (MIMO) system of DFIG into two linear Single Input Single Output (SISO) subsystems representing direct and quadrate rotor currents separately [6]-[8]. The active and reactive power control of DFIG is attained by controlling these two linear first order SISO subsystems with two PI controllers. The drawback of the vector control strategy is that the system performance depends on the DFIG parameters, especially the rotor resistance [6], [7]. Thus, the performance degrades when the parameters of DFIG used in the control system design are altered due to temperature variation, saturation, etc.

To solve this problem, we have replaced the conventional proportional integral controller with a fractional order proportional integral one which is a generalization of the former [9], [10]. The fractional order PI controller has a potential to increase system robustness and improve the system performance with the additional parameter $\lambda$, which is the fractional order of the integration action [11], [12]. 
In this work, our contribution to DFIG robust control is the use of a simple and practical fractional order PI controller, which leads to good dynamic performance and robustness of DFIG in both healthy and critical conditions.

In section 2, we introduce a brief description of the wind energy conversion system to be studied. Then, the construction of a mathematical model for each component (DFIG and wind turbine) of the wind system is presented in section 3. Next, the control strategy is developed in section 4. The design of fractional order PI controller is established in section 5 followed by the simulation results and discussion in Section 6. Finally, we complete this work with a conclusion.

\section{SYSTEM DESCRIPTION}

The WECS to be studied is presented in Figure 1. This system consists of a wind turbine driving a DFIG through a gearbox. The rotor is connected through two converters, and the stator of the DFIG is directly connected to the grid.

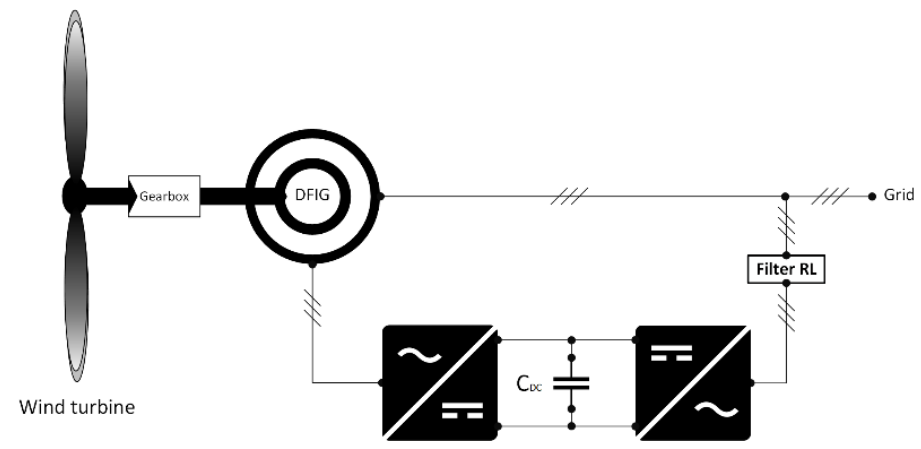

Figure 1. DFIG-based WECS structure

\section{MODELING OF THE SYSTEM}

\subsection{Wind turbine model}

In WECS, due to the different losses, the extracted power available on the rotor of the wind turbine can be expressed as [13], [14]:

$$
P_{t}=\frac{1}{2} C_{p}(T S R, \beta) \rho S v^{3}
$$

where $P_{t}$ is the turbine power, $C_{p}$ is the power coefficient, $\rho$ is the air density, $\mathrm{S}$ is the swept turbine area and $v$ is the wind speed. The power coefficient is influenced by the pitch angle, $\beta$, and the tip-speed ratio, TSR $=$ $\frac{R \Omega_{t}}{v}$, where $R$ is the turbine radius and $\Omega_{t}$ is the turbine rotational speed.

The wind turbine model is shown in Figure 2, where $G$ is the speed gain of the gearbox, $T_{a e r}$ is the aerodynamical torque, $T_{g}$ is the gearbox output torque, $J$ is inertial moment, $f$ is viscous friction coefficient of the rotor, and $\Omega$ is the rotor speed.

\subsection{DFIG model}

The stator and rotor equations of the DFIG machine are derived from Park reference frame rotating at synchronous speed [15], [16], and can be described by: The stator and rotor voltage equations:

$$
\begin{aligned}
& V_{s d}=R_{s} i_{s d}+\frac{d}{d t} \varphi_{s d}-\omega_{s} \varphi_{s q} \\
& V_{s q}=R_{s} i_{s q}+\frac{d}{d t} \varphi_{s q}+\omega_{s} \varphi_{s d} \\
& V_{r d}=R_{r} i_{r d}+\frac{d}{d t} \varphi_{r d}-\left(\omega_{s}-\omega\right) \varphi_{r q}
\end{aligned}
$$




$$
V_{r q}=R_{r} i_{r q}+\frac{d}{d t} \varphi_{r q}+\left(\omega_{s}-\omega\right) \varphi_{r d}
$$

where $V_{s d}$ and $V_{s q}$ are the direct and quadrate components of stator voltage $(\mathrm{V}), V_{r d}$ and $V_{r q}$ are the direct and quadrate components of rotor voltage $(\mathrm{V}), i_{s d}$ and $i_{s q}$ are the direct and quadrate components of stator current (A), $i_{r d}$ and $i_{r q}$ are the direct and quadrate components of rotor current (A), $R_{s}$ and $R_{r}$ are the stator and rotor resistances $(\Omega)$ and $\omega_{s}$ and $\omega_{r}$ are the stator and rotor pulsations ( $\left.\mathrm{rad} / \mathrm{s}\right)$.

The stator and rotor flux equations:

$$
\begin{aligned}
& \varphi_{s d}=L_{s} i_{s d}+L_{m} i_{r d} \\
& \varphi_{s q}=L_{s} i_{s q}+L_{m} i_{r q} \\
& \varphi_{r d}=L_{r} i_{r d}+L_{m} i_{s d} \\
& \varphi_{r q}=L_{r} i_{r q}+L_{m} i_{s q}
\end{aligned}
$$

where $\varphi_{s d}$ and $\varphi_{s q}$ are the direct and quadrate components of stator flux (wb), $\varphi_{r d}$ and $\varphi_{r q}$ are the direct and quadrate components of rotor flux (wb), $L_{m}$ is the mutual inductance $(\mathrm{H})$ and $L_{s}$ and $L_{r}$ are the stator and rotor inductances $(\mathrm{H})$.

The electromagnetic torque equation is given by:

$$
T_{e m}=P L_{m}\left(i_{r d} i_{s q}-i_{r q} i_{s d}\right)
$$

where $P$ is the number of pole pairs.

\section{CONTROL STRATEGY}

\subsection{Wind turbine control}

In order to extract maximum power from the wind, we apply the Maximum Power Point Tracking based on the rotor speed control. The tip-speed ratio is tuned to $T S R_{\text {optimal }}$ over different wind speeds $v$, by adapting the rotor speed $\Omega$ to $\Omega_{-} r e f=(G v$ TSR_optimal $) / R$ [17]. The MPPT scheme is shown in Figure 2.

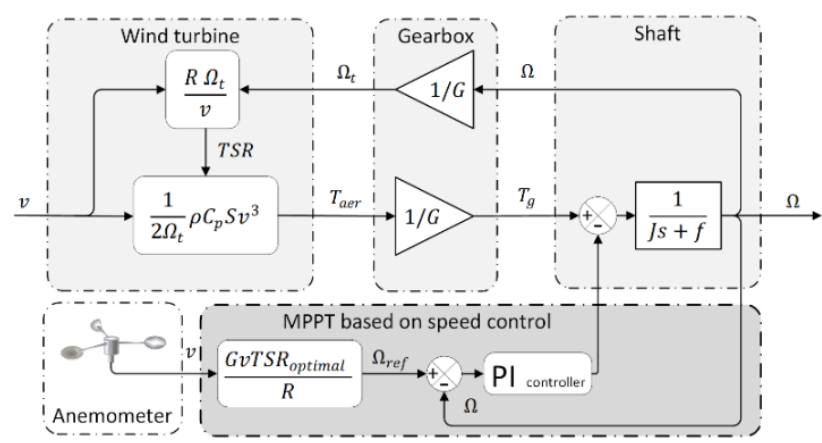

Figure 2. MPPT based on rotor speed control

\subsection{DFIG control}

We apply vector control strategy to the DFIG, which decouples the DFIG model into two independent subsystems of flux and torque, in order to get the performance similar to DC motor speed control [18]. Thus, the stator flux is chosen to be oriented to direct axis in the park reference frame $\left(\varphi_{s d}=\varphi_{s}\right.$ and $\varphi_{s q}=0$ ), and by neglecting stator resistance, $V_{s d}$ and $V_{s q}$ become: $V_{s d}=0$ and $V_{s q}=V_{s}=\omega_{s} \varphi_{s}$.

Consequently, the electromagnetic torque $\left(T_{e m_{-} D F I G}\right)$ and the active and reactive stator powers $\left(P_{S}, Q_{s}\right)$ become:

$$
T_{e m}=-P \varphi_{s} \frac{L_{m}}{L_{s}} i_{r q}
$$




$$
\begin{aligned}
& P_{s}=-V_{s} \frac{L_{m}}{L_{s}} i_{r q} \\
& Q_{s}=\frac{V_{s}^{2}}{\omega_{s} L_{s}}-V_{s} \frac{L_{m}}{L_{s}} i_{r d}
\end{aligned}
$$

Also, the rotor voltages can be expressed as:

$$
\begin{aligned}
& V_{r d}=R_{r} i_{r d}+\left(L_{r}-\frac{L_{m}^{2}}{L_{s}}\right) \frac{d i_{r d}}{d t}-\operatorname{slip} \omega_{s}\left(L_{r}-\frac{L_{m}^{2}}{L_{s}}\right) i_{r q} \\
& V_{r q}=R_{r} i_{r q}+\left(L_{r}-\frac{L_{m}^{2}}{L_{s}}\right) \frac{d i_{r q}}{d t}+\operatorname{silp} \omega_{s}\left(L_{r}-\frac{L_{m}^{2}}{L_{s}}\right) i_{r d}+\operatorname{slip} \frac{L_{m} V_{s}}{L_{s}}
\end{aligned}
$$

where slip is the slip of DFIG.

The proposed control plan of DFIG based on two FOPI controllers is shown in Figure 3.

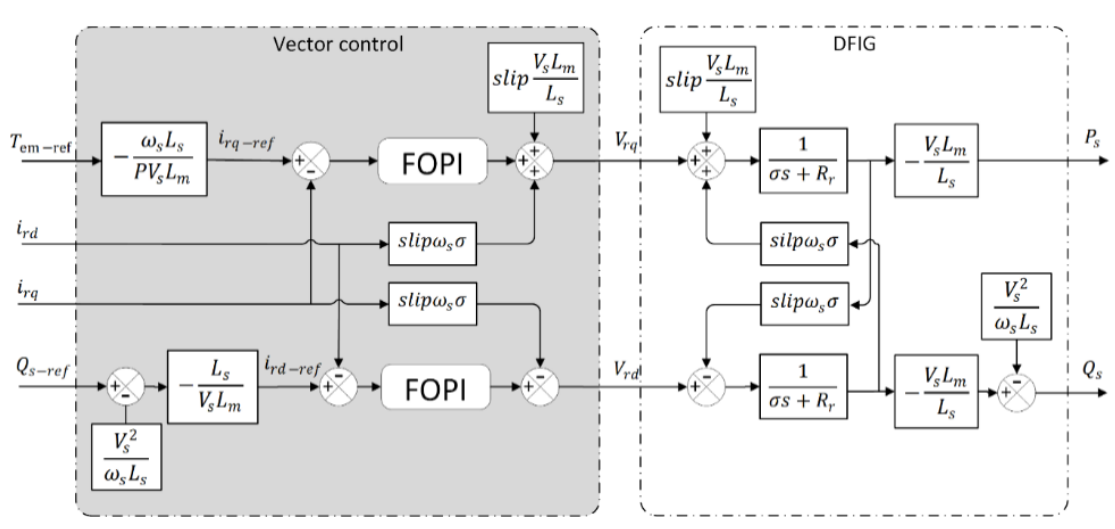

Figure 3. The control scheme of DFIG with FOPI controllers

\section{FRACTIONAL ORDER PI CONTROLLER TUNING PROCEDURE}

In the previous section, the general form of the transfer function of the plants was:

$$
P(s)=\frac{K}{T s+1}
$$

where $\mathrm{T}$ and $\mathrm{K}$ are constants.

In this section, two different controllers are proposed: the integer order PI and the Fractional Order PI (FOPI). The transfer functions of the two controllers can be described as follows:

$$
\begin{aligned}
& C_{P I}(s)=K_{p}\left(1+\frac{K_{i}}{s}\right) \\
& C_{F O P I}(s)=K_{p}\left(1+\frac{K_{i}}{s^{\lambda}}\right)
\end{aligned}
$$

where $K_{p}, K_{i}$ and $\lambda$ are real numbers, $\lambda \in[0,1]$.

\subsection{Design specifications}

In [19], [20], a tuning method for PI controller and FOPI controller is proposed. We choose the gain crossover frequency, $\omega_{c}$, and phase margin, $\varphi_{m}$, to be the same for both controllers. For the system stability and robustness, the following constraints are considered: [19], [20]

a) Phase margin constraint:

$$
\operatorname{Arg}\left[G\left(j \omega_{c}\right)\right]=\operatorname{Arg}\left[C\left(j \omega_{c}\right) P\left(j \omega_{c}\right)\right]=\angle C\left(j \omega_{c}\right)+\angle P\left(j \omega_{c}\right)=-\pi+\varphi_{m}
$$


where $G(j \omega)$ is the open-loop transfer function of the system, $C(j \omega)$ is the controller transfer function and $\mathrm{P}(\mathrm{j} \omega)$ is the plant transfer function.

b) Gain cross-over frequency constraint:

$$
\left|G\left(j \omega_{c}\right)\right|_{d B}=\left|C\left(j \omega_{c}\right) P\left(j \omega_{c}\right)\right|_{d B}=0
$$

c) Robustness to loop gain variations, which demands that the phase Bode plot to be flat at the gain crossover frequency, $\omega_{c}$, i.e., the derivative of the open loop phase, at the gain cross-over frequency, to be equal to zero:

$$
\left.\frac{d\left(\operatorname{Arg}\left[G\left(j \omega_{c}\right)\right]\right)}{d \omega}\right|_{\omega=\omega_{c}}=0
$$

\subsection{Fractional order PI controller Tuning}

Based on the design specifications introduced in the previous section, we present the tuning procedure of the Fractional Order PI controller, for the first order plant.

The open-loop transfer function with the FOPI controller is,

$$
G(s)=C_{F O P I}(s) P(s)=K_{p}\left(1+\frac{K_{i}}{s^{\lambda}}\right)\left(\frac{K}{T s+1}\right)
$$

where $\mathrm{K}$ and $\mathrm{T}$ are known and $K_{p}, K_{i}$ and $\lambda$ should be designed in the controller design process. The FOPI controller can be expressed as:

$$
C_{F O P I}(s)=K_{p}\left(1+\frac{K_{i}}{s^{\lambda}}\right)=K_{p}\left(1+\frac{K_{i}}{(j \omega)^{\lambda}}\right)
$$

Since $j=e^{\pi / 2}$, thus $j^{\lambda}=e^{\lambda \pi / 2}=\cos (\lambda \pi / 2)+j \sin (\lambda \pi / 2)$, which gives,

$$
C_{F O P I}(s)=K_{p}\left(1+\frac{K_{i} \omega^{-\lambda}}{\cos (\lambda \pi / 2)+j \sin (\lambda \pi / 2)}\right)
$$

The open-loop phase at the gain cross-over frequency is,

$$
\operatorname{Arg}|G(j \omega c)|=-\arctan \frac{K_{i} \omega_{c}^{-\lambda} \sin (\lambda \pi / 2)}{1+K_{i} \omega_{c}^{-\lambda} \cos (\lambda \pi / 2)}-\arctan \left(\omega_{c} T\right)
$$

According to the first design constraint (a),

$$
\operatorname{Arg}|G(j \omega c)|=-\arctan \frac{K_{i} \omega_{c}^{-\lambda} \sin (\lambda \pi / 2)}{1+K_{i} \omega_{c}^{-\lambda} \cos (\lambda \pi / 2)}-\arctan \left(\omega_{c} T\right)=-\pi+\varphi_{m}
$$

Hence, the relationship between $K_{i}$ and $\lambda$ can be established as,

$$
K_{i}=\frac{-\tan \left[\arctan \left(\omega_{c} T\right)+\varphi_{m}\right]}{\omega_{c}^{-\lambda} \sin (\lambda \pi 2)+\omega_{c}^{-\lambda} \cos (\lambda \pi 2) \tan \left[\arctan \left(\omega_{c} T\right)+\varphi_{m}\right]}
$$

And the open-loop gain using at the crossover frequency:

$$
\left|G\left(j \omega_{c}\right)\right|=\frac{K K_{p} \sqrt{\left[K_{i} \omega_{c}^{-\lambda} \sin (\lambda \pi / 2)\right]^{2}+\left[1+K_{i} \omega_{c}^{-\lambda} \cos (\lambda \pi / 2)\right]^{2}}}{\sqrt{\left(T \omega_{c}\right)^{2}+1}}
$$

Additionally, according to the second constraint (b):

$$
\frac{K K_{p} \sqrt{\left[K_{i} \omega_{c}^{-\lambda} \sin (\lambda \pi / 2)\right]^{2}+\left[1+K_{i} \omega_{c}^{-\lambda} \cos (\lambda \pi / 2)\right]^{2}}}{\sqrt{\left(T \omega_{c}\right)^{2}+1}}=1
$$

Also, according to the third constraint (c): 


$$
\left.\frac{d\left(\operatorname{Arg}\left[G\left(j \omega_{c}\right)\right]\right)}{d \omega}\right|_{\omega=\omega_{c}}=\frac{K_{i} \lambda \omega_{c}^{\lambda-1} \sin (\lambda \pi / 2)}{\omega_{c}^{2 \lambda}+2 K_{i} \omega_{c}^{-\lambda} \cos (\lambda \pi / 2)+K_{i}^{2}}-\frac{T}{\left(T \omega_{c}\right)^{2}+1}=0
$$

Moreover, another equation about $K_{i}$ can be established as: $C \omega_{c}^{-2 \lambda} K_{i}^{2}+B K_{i}+C=0$ where, $B=2 C \omega_{c}^{-\lambda} \sin (\lambda \pi / 2)-\lambda \omega_{c}^{-\lambda-1} \sin (\lambda \pi / 2)$ and $C=\frac{T}{\left(T \omega_{c}\right)^{2}+1}$ Thus,

$$
K_{i}=\frac{-B \pm \sqrt{B^{2}-4 C^{2} \omega_{c}^{-2 \lambda}}}{2 C \omega_{c}^{-2 \lambda}}
$$

The Equations (27), (29) and (31) of the three variables $\lambda, K_{i}$ and $K_{p}$ can be solved easily by different approaches.

For tuning the FOPI controller and classical PI controller for the rotor current control loop, the same cross-over frequency, $\omega_{c}$, is presumed: $\omega_{c}=500 \mathrm{rad} / \mathrm{s}$. Furthermore, in order to get a damping ratio of $\xi=$ 0.707, the phase margin should be the same for both controllers: $\varphi_{m}=64^{\circ}$. Hence, the tuned current controllers give,

$$
\begin{aligned}
& C_{F O P I}(s)=0.0763\left(1+\frac{50.16}{s^{0.5441}}\right) \\
& C_{P I}(s)=0.0792\left(1+\frac{25.0916}{s}\right)
\end{aligned}
$$

\section{RESULTS AND DISCUSSION}

In order to verify and study the efficiencies of the control strategy, two sets of simulations were performed. The first set is carried out on an isolated DFIG current control loop to prove the effectiveness of the proposed controller design. Whereas, the second one is carried out on DFIG-based WECS to confirm the dynamic of the whole system. The WECS system's parameters used during simulations are listed in Table 1.

Table 1. Doubly fed induction generator and wind turbine parameters

\begin{tabular}{cccc}
\hline \multicolumn{2}{c}{ Doubly fed induction generator parameters } & \multicolumn{2}{c}{ Wind turbine parameters } \\
\hline Rated power, $P_{n}$ & $1.5 \mathrm{MW}$ & Blade radius, $R$ & $41 \mathrm{~m}$ \\
Stator rated voltage, $V_{s}$ & $398 / 690 \mathrm{~V}$ & Number of blades & 3 \\
Stator rated frequency, $f_{s}$ & $50 \mathrm{~Hz}$ & Gearbox ratio, $G$ & 80 \\
Stator inductance, $L_{s}$ & $0.0137 \mathrm{H}$ & Maximal power coefficient, $C_{p-\text { max }}$ & $0.55\left(\right.$ TSR $_{\text {optimal }}=8.12$ and $\left.\beta=0^{\circ}\right)$ \\
Rotor inductance, $L_{r}$ & $0.0136 \mathrm{H}$ & & \\
Mutual inductance, $L_{m}$ & $0.0135 \mathrm{H}$ & & \\
Stator resistance, $R_{s}$ & $0.012 \Omega$ & & \\
Rotor resistance, $R_{r}$ & $0.021 \Omega$ & & \\
Number of pair of poles, $P$ & 2 & & \\
\hline
\end{tabular}

Case 1: The isolated DFIG (without WECS) current control loop

This simulation analyses and compares the performance of the FOPI controller with the classical PI controller of the DFIG current control loop. Under four different specifications, i.e. the set-point reference, the robustness, the disturbance rejection and the noise minimization.

Figure 4 shows the unit step responses of the DFIG current control loop with the FOPI controller as shown in Figure 4(a), and classical PI controller as shown in Figure 4(b). The unit step responses are designed with three different closed-loop gain $(K): \frac{1}{R_{r}}, 2 \frac{1}{R_{r}}$ and $0.5 \frac{1}{R_{r}}$. It is clear that the FOPI controller exhibits a good reference tracking and, on contrary to the classical PI controller, its overshoots were not affected by the different gains. Therefore, the controlled system using the fractional controller remains robust over gain changes. 
(a)

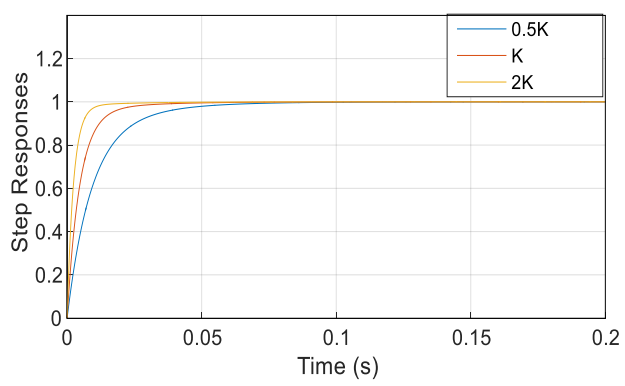

(b)

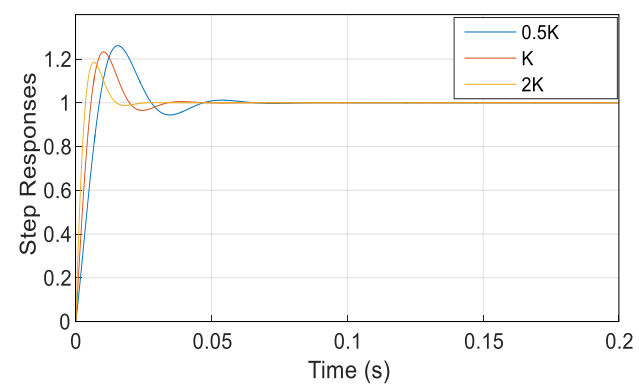

Figure 4. Step current responses: (a) with FOPI controller, (b) with classical PI controller

The unit step responses of DFIG current control loop with the FOPI controller and the classical PI controller are depicted in Figure 5. A disturbance of 0.5 is applied on the output of the plant from $t=0.2 \mathrm{~s}$ on, and a measurement noise with Gaussian distributed random signal with zero mean and 0.1 variance value is assumed in the output of the plant from $t=0.4 \mathrm{~s}$ on. By comparing the two curves we notice that a faster disturbance-rejection, and better minimization of the measurement noise effect is achieved using the FOPI controller, indicating superior disturbance-rejection and measurement noise minimization for the controlled system with the fractional controller.

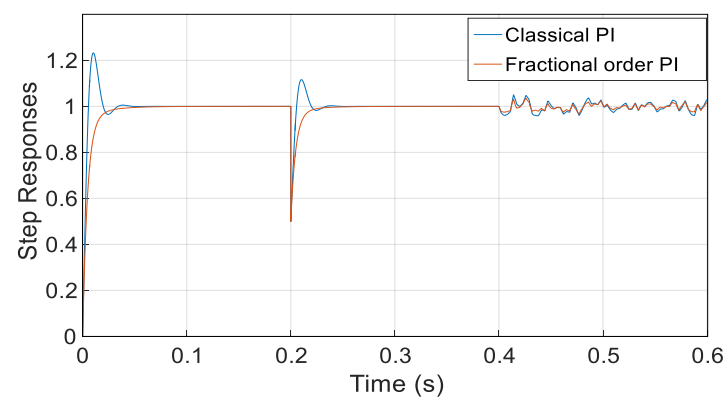

Figure 5. Step current responses using FOPI controller and classical PI controller

Case 2: the DFIG-based wind energy conversion system

In this case, we simulated the DFIG inside wind energy conversion system using the classical PI and the FOPI controllers. The following simulation results were obtained for reactive stator power reference $Q_{s-r e f}=0$ and wind speed profile modeled using the sum of harmonics [21], [22]:

$$
v(t)=8+0.2 \sin (0.10 t)+2 \sin (0,35 t)+\sin (1.235 t)+0.2 \sin (3.5 t)
$$

Furthermore, a disturbance of $500 \mathrm{~A}$ is applied on the output of the currents plants from $t=10 \mathrm{~s}$ on, and a Gaussian distributed random signal measurement noise with zero mean and 30 variance value is assumed in the output of the currents plants from $t=20 \mathrm{~s}$ on.

Figures 6(a), (b), (c) and (d) present the evolution with time of the wind speed, the power coefficient, the wind turbine power and DFIG slip, respectively. As shown in Figure 6(b), the power coefficient $C_{p}$ achieved a maximum value 0.55 rapidly and remains constant over wind speed evolution. However, the wind turbine power and the slip vary according to the wind speed profile.

Electromagnetic torque, stator active and reactive powers of the DFIG are shown respectively in Figure 7(a), (b) and (c). From these figures it is clear that the WECS with the FOPI controller exhibits better dynamic performance in terms of the set-point reference, the disturbance rejection and the noise minimization, than the WECS with classical PI controller. 
(a)

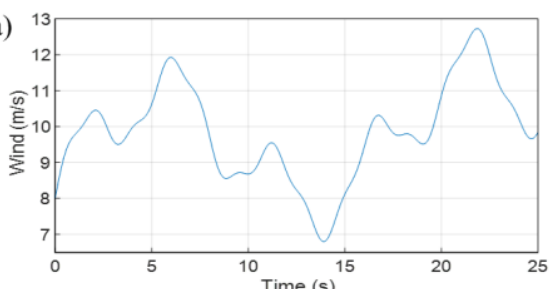

(c)

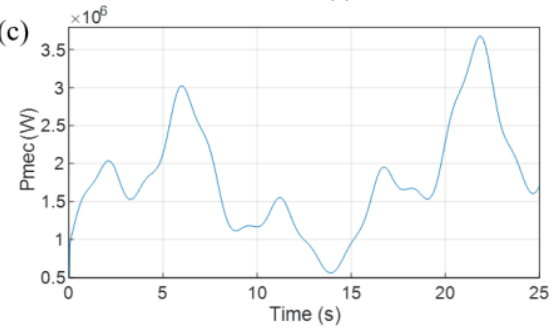

(b)

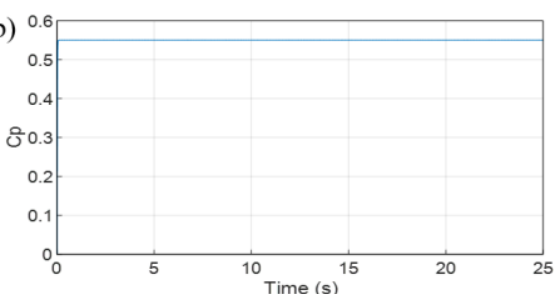

(d)

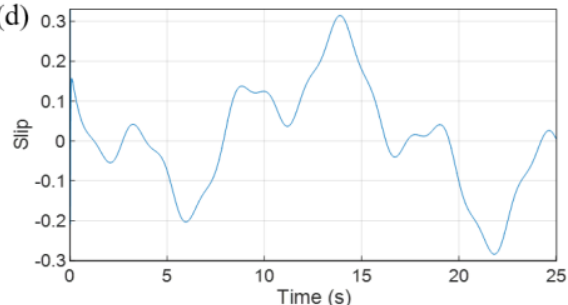

Figures 6. (a) Wind speed profile, (b) power coefficient, (c) wind turbine power and, (d) DFIG slip
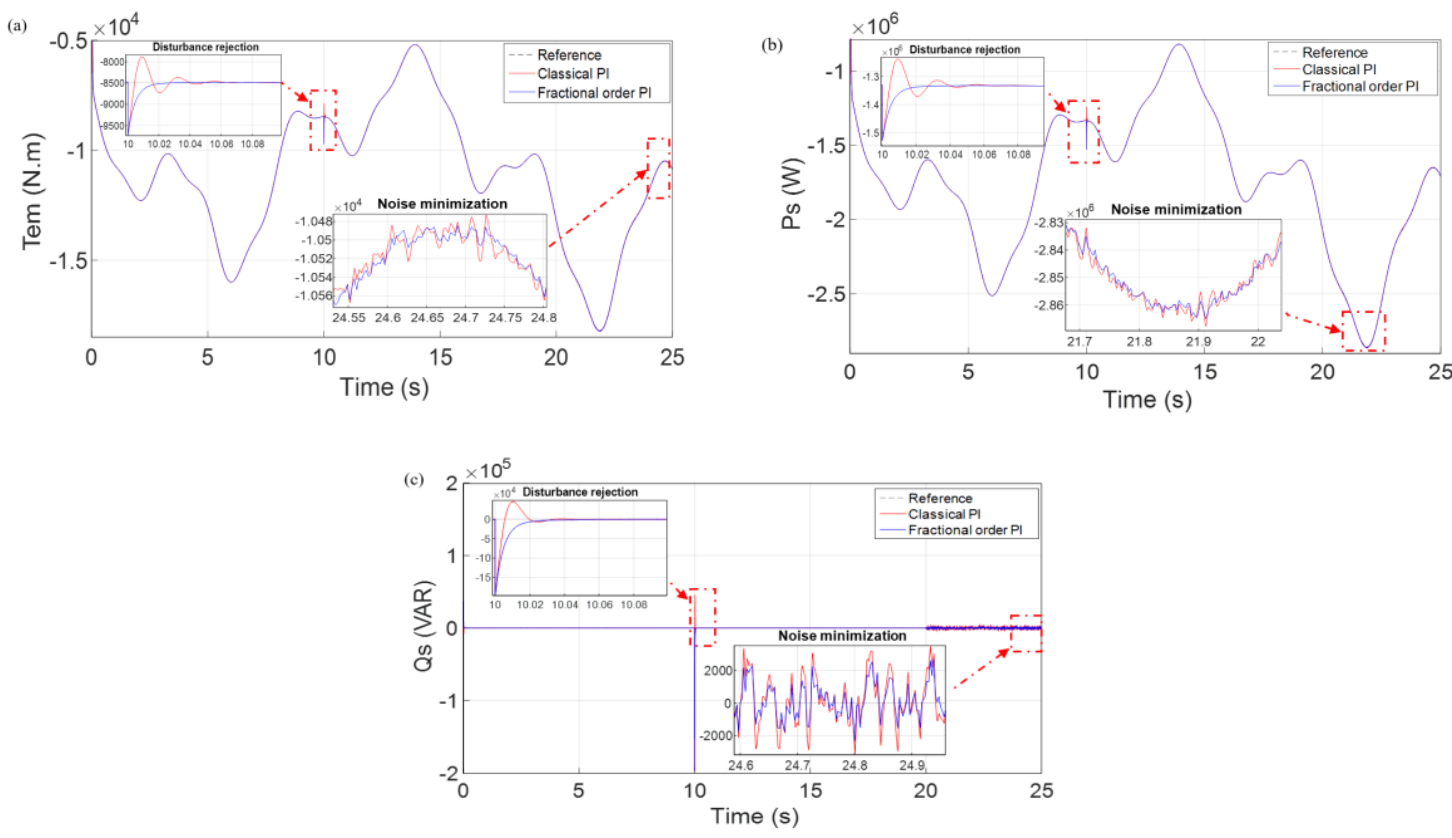

Figure 7. (a) Electromagnetic torque, (b) stator active power, (c) stator reactive powers

\section{CONCLUSION}

In this paper, we proposed a robust control of a variable speed DFIG-based WECS using vector control strategy based on two Fractional Order PI Controllers, to prevent system deterioration under critical conditions, namely: DFIG parameters variation, disturbance and measurement noise. The two Fractional Order PI controllers were designed with a simple analytical method. The simulation results show that the WECS with the FOPI controllers exhibit better dynamic performance even in critical conditions. This is reflected in the robustness to rotor resistance variation, superior disturbance-rejection and measurement noise minimization.

\section{REFERENCES}

[1] Yang B, Yu T, Shu H, et al. Robust sliding-mode control of wind energy conversion systems for optimal power extraction via nonlinear perturbation observers. Appl Energy 2018; 210: 711-723.

[2] Abdelmalki F, Ouaaline N. T-S Fuzzy observer and controller of Doubly-Fed Induction Generator. International Journal Power Electron Drive System (IJPEDS) 2016; 7: 617. 
[3] Babu NR, Arulmozhivarman P. Wind energy conversion systems-a technical review. J Eng Sci Technol 2013; 8: 493-507.

[4] Liserre M, Cardenas R, Molinas M, et al. Overview of Multi-MW Wind Turbines and Wind Parks. IEEE Trans Ind Electron 2011; 58: 1081-1095.

[5] Azzaoui ME, Mahmoudi H, Boudaraia K. Backstepping Control of Wind and Photovoltaic Hybrid Renewable Energy System. International Journal Power Electron Drive System (IJPEDS) 2016; 7: 677-687.

[6] Taveiros FEV, Barros LS, Costa FB. Back-to-back converter state-feedback control of DFIG (doubly-fed induction generator)-based wind turbines. Energy 2015; 89: 896-906.

[7] Zhi D, Xu L, Morrow J. Improved Direct Power Control of Doubly-Fed Induction Generator Based Wind Energy System. In: 2007 IEEE International Electric Machines Drives Conference. 2007, pp. 436-441.

[8] Pena R, Clare JC, Asher GM. Doubly fed induction generator using back-to-back PWM converters and its application to variable-speed wind-energy generation. IEE Proc-Electr Power Appl 1996; 143: 231-241.

[9] Boudjehem B, Boudjehem D. Parameter Tuning of a Fractional-Order PI Controller Using the ITAE Criteria. In: Baleanu D, Machado JAT, Luo ACJ (eds) Fractional Dynamics and Control. New York, NY: Springer New York, pp. 49-57.

[10] Podlubny I. Fractional-order systems and $\mathrm{PI}^{\lambda} \mathrm{D}^{\mu}$-controllers. IEEE Trans Autom Control 1999; 44: 208-214.

[11] Jiacai H, Hongsheng L, Fulin T, et al. Fractional order sliding mode controller for the speed control of a permanent magnet synchronous motor. In: Control and Decision Conference (CCDC), 2012 24th Chinese. IEEE, 2012, pp. 1203-1208.

[12] Oustaloup A, Sabatier J, Lanusse P. From fractal robustness to the CRONE control. FCAA 1999; 2: 1-30.

[13] Heier S. Grid integration of wind energy: onshore and offshore conversion systems. Third editon. Chichester, West Sussex, United Kingdom: Wiley, 2014.

[14] Zaragoza J, Pou J, Arias A, et al. Study and experimental verification of control tuning strategies in a variable speed wind energy conversion system. Renew Energy 2011; 36: 1421-1430.

[15] Altun H, Sünter S. Modeling, simulation and control of wind turbine driven doubly-fed induction generator with matrix converter on the rotor side. Electr Eng 2013; 95: 157-170.

[16] Bharti OP, Saket RK, Nagar SK. Controller design for doubly fed induction generator using particle swarm optimization technique. Renew Energy 2017; 114: 1394-1406.

[17] Boukhezzar B, Siguerdidjane H. Nonlinear control with wind estimation of a DFIG variable speed wind turbine for power capture optimization. Energy Convers Manag 2009; 50: 885-892.

[18] Fan L, Miao Z. Modeling and analysis of doubly fed induction generator wind energy systems. New York: Academic Press, 2015.

[19] Luo Y, Chen YQ, Wang CY, et al. Tuning fractional order proportional integral controllers for fractional order systems. J Process Control 2010; 20: 823-831.

[20] Li H, Luo Y, Chen Y. A fractional order proportional and derivative (FOPD) motion controller: tuning rule and experiments. IEEE Trans Control Syst Technol 2010; 18: 516-520.

[21] Attoui I, Omeiri A. Modeling, control and fault diagnosis of an isolated wind energy conversion system with a selfexcited induction generator subject to electrical faults. Energy Convers Manag 2014; 82: 11-26.

[22] Mirecki A, Roboam X, Richardeau F. Architecture Complexity and Energy Efficiency of Small Wind Turbines. IEEE Trans Ind Electron 2007; 54: 660-670. 